\title{
Pelatihan Pembuatan Souvenir Sabun Kepada Kelompok Ibu-Ibu Rumah Tangga Kecamatan Kaliwates Kabupaten Jember Dalam Rangka Meningkatkan Perekonomian Masyarakat
}

\author{
Dwi Koko Pratoko ${ }^{1)}$ Nia Kristiningrum ${ }^{1)}$ \\ Adelia A Devi ${ }^{1)} \quad$ Regol S Raudiah ${ }^{1)}$ \\ 1) Universitas Jember \\ dwikoko.farmasi@unej.ac.id
}

\begin{abstract}
ABSTRAK: Sasaran dari kegiatan pengabdian masyarakat ini adalah kelompok ibu-ibu rumah tangga di Kecamatan Kaliwates Jember. Metode pelaksanaan dari kegiatan ini dibagi menjadi beberapa tahap yaitu persiapan, pelaksanaan pelatihan pembuatan souvenir sabun dan pelatihan pembuatan toko daring. Peserta dibagi menjadi kelompok-kelompok kecil sehingga sangat efektif dalam meningkakan pemahaman dan keterampilan kerja peserta. Adanya kegiatan ini diharapkan dapat memberikan ide, pengetahuan dan keterampilan bagi kelompok ibu rumah tangga tersebut sehingga mempunyai rumah produksi souvenir sabun dan harapannya bisa meningkatkan perekonomian keluarganya.
\end{abstract}

Kata kunci : sabun, souvenir, kelompok ibu rumah tangga

ABSTRACT: The target of this community service activity is a group of housewives in Kaliwates District, Jember. The method of implementation of this activity is divided into several stages, namely preparation, training in making soap and training in making online store. Participants are divided into small groups so that it is very effective in increasing participants understanding and work skills. The existence of this activity is expected to provide ideas, knowledge and skills for the group of housewives so that they have a soap souvenir production house and hope to improve the family's economy.

Keywords: soaps, souvenir, group of housewifes

\section{PENDAHULUAN}

Pada era modern ini, teknologi semakin maju dengan pesat sehingga harus diimbangi dengan peningkatan kualitas sumber daya manusia. Lapangan pekerjaan yang semakin sempit mendorong manusia untuk berusaha menciptakan lapangan pekerjaan sendiri. Dalam rangka menciptakan suatu lapangan pekerjaan, maka dibutuhkan keterampilan dibidang usaha tertentu, pandai melihat kebutuhan pasar serta dapat mengetahui kemampuan ekonomi masyarakat di sekitarnya.

Tuntutan kebutuhan hidup yang semakin meningkat membuat masyarakat terus berusaha untuk meningkatkan perekonomiannya. Wanita dalam keluarga juga mengalami tuntutan yang sama, dimana dewasa ini semakin banyak wanita yang ikut membantu perekonomian keluarga. Saat ini emansipasi wanita juga diperlukan untuk bisa meningkatkan perekonomian di dalam suatu keluarga.

Sasaran pada kegiatan ini adalah kelompok ibu-ibu PKK di Kelurahan Tegal Besar Kecamatan Kaliwates Jember. Secara rutin ibu-ibu PKK ini selalu mengadakan 
pertemuan rutin tiap bulannya dan membahas topik-topik tertentu yang terkait dengan kegiatan PKK. Kelompok ibu-ibu PKK ini kebanyakan adalah tamatan SMP dan SMA dan sebagian besar tidak bekerja atau hanya berprofesi sebagai ibu rumah tangga. Untuk memperoleh pekerjaan di luar sangatlah sulit karena faktor kualifikasi pndidikan, sedangkan untuk membuka usaha sendiri terkendala oleh keterbatasan keterampilan dan modal yang dimiliki, padahal sebenarnya kelompok ini memiliki semangat yang tinggi untuk bisa memiliki pendapatan sendiri dan kebutuhan rumah tangga semakin meningkat dan pendapatan relatif tetap. Sehingga ibu-ibu PKK ingin berperan serta dalam meningkatkan perekonomian keluarga. Selain itu kendala-kendala yang disebutkan diatas, kelompok tersebut juga tidak memiliki ide usaha dan tidak memiliki pengetahuan untuk rencana pemasarannya. Hal-hal tersebut yang membuat kelompok ibu-ibu rumah tangga ini tidak memiliki semangat untuk berwirausaha.

\section{PERMASALAHAN}

Berdasarkan analisis situasi yang dialami mitra, dapat ditarik kesimpulan permasalahan dari mitra yang mendasari dilakukan program pengabdian masyarakat ini antara lain:

1. Ibu-ibu PKK Kelurahan Tegal Besar Kecamatan Kaliwates Kabupaten Jember hanya melakukan pertemuan rutin PKK yang bersifat non produktif. Sedangkan untuk menuju kelompok yang produktif secara perekonomian, ibu-ibu PKK tidak memiliki ide usaha yang diharapkan mampu meningkatkan perekonomian.

2. Minimnya keterampilan yang dimiliki oleh ibu-ibu Rumah tangga terutama yang menunjang perekonomian keluarga

3. Minimnya pengetahuan tentang trik pemasaran hasil usaha

\section{Tujuan}

Berdasarkan analisis permasalahan diatas, pengabdian kepada masyarakat ini memiliki tujuan sebagai berikut :

1. Memberikan ide usaha bagi kelompok ibu-ibu rumah tangga terutama PKK

Kelurahan Tegal Besar Kecamatan Kaliwates Kabupaten Jember yaitu usaha souvenir sabun

2. Memberikan keterampilan berupa pelatihan pembuatan sabun serta pengemasan souvenir kepada kelompok ibu-ibu rumah tangga

3. Memberikan pelatihan pembuatan toko daring yang merupakan bagian dari pemasaran hasil usaha yang ke depannya guna pemasaran souvenir sabun serta sabun herbal. 


\section{Manfaat}

Berdasarkan tujuan pengabdian kepada masyarakat yang dilakukan, beberapa manfaat yang diperoleh dari ini antara lain bertambahnya pengetahuan ibu ibu rumah tangga terkait peluang usaha baru bagi kelompok ibu-ibu rumah tangga yang berpotensi membantu meningkatkan perekonomian keluarga.Selain manfaat tersebut, manfaat lain yang didapat adalah bertambahnya keterampilan ibu-ibu rumah tangga dalam pembuatan sabun yang dapat digunakan sebagai souvenir sabun ataupun sebagai sabun herbal yang memberikan peluang usaha yang cukup bagus untuk dikembangkan. Manfaat terakhir yang diperoleh adalah kelompok ibu rumah tangga mampu mengelola pemasaran produk yang dibuat dalam toko daring dalam rangka memasarkan dan meningkatkan luasan pemasaran produk. Dimana kesemua manfaat tersebut adalah dalam rangka meningkatkan perekonomian masyarakat pada umumnya serta ibu rumah tangga Kelurahan Tegal Besar Kecamatan Kaliwates Kabupaten Jember pada khususnya.

\section{METODE PELAKSANAAN}

Metode pelaksanaan kegiatan pengabdian masyarakat ini dilakukan menjadi beberapa tahap yaitu penyusunan materi pelatihan. Materi yang disampaikan kepada ibuibu PKK dipersiapkan sebaik mungkin dengan mempertimbangkan tingkatan Pendidikan ibu-ibu rumah tangga Kelurahan Tegal Besar Kecamatan Kaliwates Kabupaten Jember. Rincian bahan, alat dan juga cara pembuatan sabun disajikan dengan kata-kata yang sederhana dan mudah dipahami oleh peserta pelatihan. Petunjuk pembuatan sabun juga dibuat dalam bentuk tertulis dan dibagikan pada peserta pelatihan.

Tahap selanjutnya adalah pelaksanaan pelatihan pembuatan sabun serta pengemasan souvenir sabun. Dalam kegiatan ini, tim pelaksana memberikan motivasi terlebih dahulu kepada mitra agar memiliki keinginan dan rasa percaya diri dalam berwirausaha. Langkah selanjutnya tim pengusul mendatangkan pemateri pelatihan pembuatan sabun yang sudah berpengalaman untuk memberikan pelatihan pembuatan sabun. Dalam kegiatan ini pemateri memberikan sekilas pengetahuan metode pembuatan sabun serta diberikan demo cara pembuatan sabun yang kemudian dilanjutkan dengan peserta pelatihan mempraktekkan sendiri cara pembuatan sabun. Setelah produk sabun sudah jadi, peserta juga diberikan contoh cara pengemasannya sehingga menarik dan meningkatkan nilai dari produk. Peralatan dan bahan disediakan oleh tim pengusul, sedangkan tempat pelatihan dilaksanakan di salah satu rumah warga.

Tahap terakhir kegiatan pengabdian adalah mendampingi pemasaran mulai dari membantu mengidentifikasi serta menetapkan harga jual serta memberikan pelatihan pembuatan toko daring dalam rangka meningkatkan pemasaran produk yang dibuat. 


\section{HASIL DAN PEMBAHASAN}

\section{Hasil}

Kegiatan pengabdian masyarakat ini memberikan beberpaa hasil yang antara lain ditunjukkan sebagai berikut :

1. Produk sabun dengan berbagai aroma, bentuk dan warna.

Berdasarkan pelatihan yang dilakukan aroma yang ditambahkan antara lain, wangi bunga, sereh, aroma sabun komersial serta aroma-aroma lan yang berpotensi dikembangkan. Produk sabun tersebut kemudian dikemas sehingga meningkatkan penampilan sehingga lebi berpotensi untuk dijual.

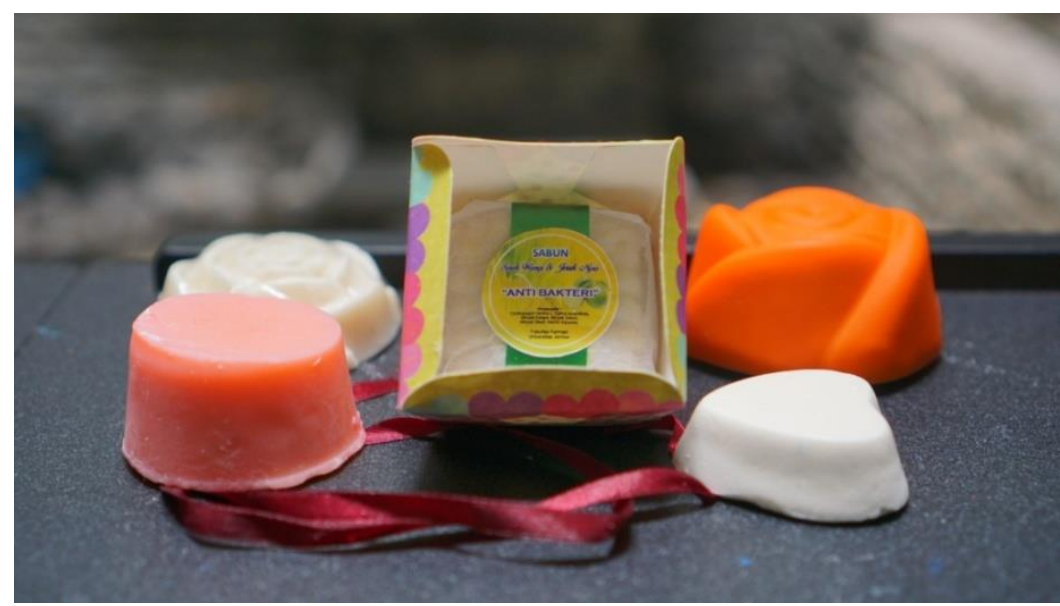

Gambar 1. Hasil pelatihan pembuatan souvenir sabun

2. Toko daring

Adapun toko daring yang diberikan pelatihan adalah toko daring berbasis aplikasi android. Toko daring yang disarankan tim pelaksana adalah toko toko daring yang sudah tenar di masyarakat untuk meningkatan peluang lakunya di pasaran. Adapun toko daring yang dapat dipilih antara lain Shopee, Tokopedia, Bukalapak, Olx dan beberapa toko daring lainnya. Tangkapan layar dari toko yang telah dibuat oleh peserta dan yang sudah dimasukkan salah satu sampel souvenir serta sabun herbal ditunjukkan pada gambar 2 .. 

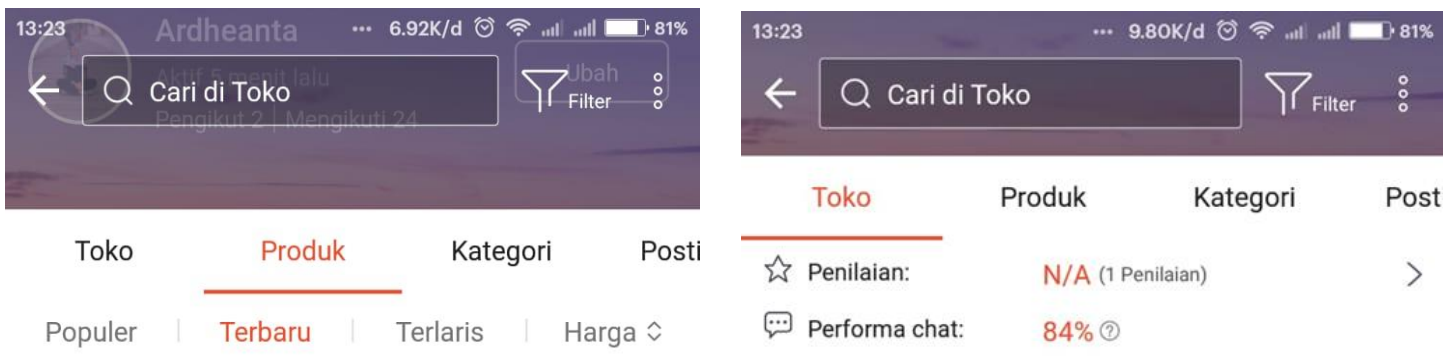

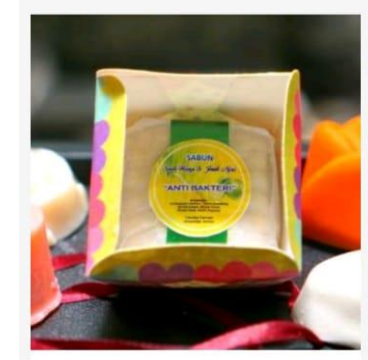

Sabun sereh wangi dan jeruk nipis
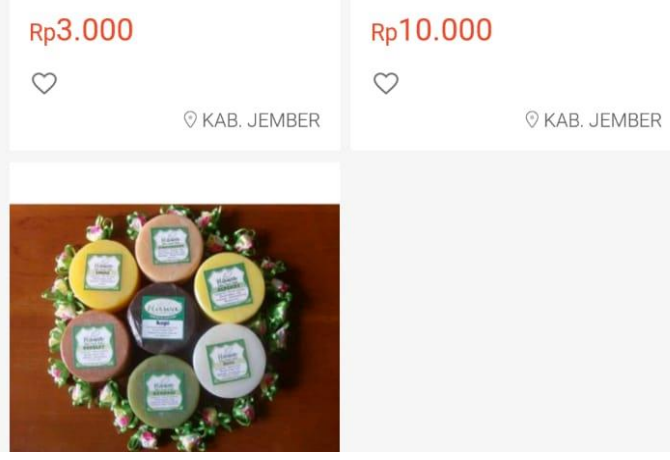

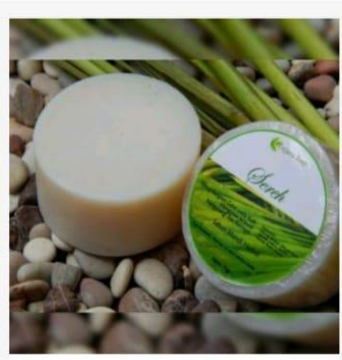

Sabun Serah Alami Rp10.000 O KAB. JEMBER

\section{Pembahasan}

Gambar 2. Tangkapan layar toko daring hasil pelatihan

$$
\begin{aligned}
& \text {-Unit Usaha Ibu-ibu PKK } \\
& \text {-Menyediakan souvenir sabun herbal } \\
& \text {-Produk original } \\
& \text {-Harga terjangkau dengan Kualitas Terjamin, } \\
& \text { Insyaallah Bermanfaat }
\end{aligned}
$$

Tautan Toko: shopee.co.id/ardeantaa
Akun Terverifikasi $\square$ f

Populer | Terbaru Terlaris | Harga $\hat{v}$

Kegiatan pengabdian masyarakat yang berupa pelatihan pembuatan souvenir sabun serta pelatihan pembuatan toko daring memberikan manfaat bagi peserta. Hal ini dapat dilihat dari antusiasme peserta pelatihan. Pelatihan ini diikuti oleh 20 orang ibu-ibu rumah tangga yang mewakili beberapa Dasa Wisma (DAMA) di PKK Kecamatan Kaliwates. Pembagian peserta menjadi beberapa kelompok kecil pada saat pelatihan sangat efektif dalam meningkatkan pemahaman dan keterampilan peserta dalam membuat souvenir sabun. Dalam pelatihan pembuatan sabun, peserta sangat proaktif dalam praktik maupun bertanya. Justru dengan adanya pelatihan pembuatan sabun ini, beberapa diantara peserta memiliki ide untuk inovasi sabun ke depannya, baik terkait bentuk sabun, komposisi bahan pembuat sabun, aroma sabun, maupun cara pengemasannya. Pada pelatihan ini pun, peserta diberi wawasan pengemasan dan praktik cara mengemas souvenir untuk mempercantik tampilan dari sabun yang telah dibuat. Pengemasan produk secara signifikan akan meningkatkan nilai dari produk yang akan dijual. Pelatihan selanjutnya yang dilakukan adalah pembuatan toko daring. Pemilihan toko daring ini didasarkan pada banyaknya aplikasi toko daring yang sedang booming 
dan banyak digunakan masyarakat Indonesia. Selain hal tersebut, toko daring lebih mudah pembuatannya tidak ememlukan biaya, tidak memerlukan biaya berlangganan web. Hanya berbekal telepon genggam (HP) dan koneksi internet, maka Toko Daring dapat dibuat dan dioperasikan. Ditunjang pula semua ibu-ibu rumah tangga memiliki HP dan rata-rata sudah memiliki koneksi internet serta beberapa ibu rumah tangga sudah familiar dengan penggunaan toko daring namun hanya sebatas sebagai konsumen. Hampir semua ibu rumah tangga tidak mengetahui cara berjualan menggunakan aplikasi toko daring yang sudah dimiliki oleh mereka. Melalui pelatihan pembuatan toko daring, para peserta dapat membuat serta mengelola toko daring yang mana dapat digunakan sebagai sarana untuk penjualan produk yang dimiliki yaitu sabun herbal atau souvenir sabun. Melalui pengabdian kepada masyarakat ini ibu-ibu rumah tangga Kelurahan Tegal Besar Kecamatan Kaliwates Kabupaten Jember diharapkan dapat memanfaatkan pengetahuan dan keterampilannya untuk bisa meningkatkan perekonomian keluarganya.

\section{KESIMPULAN DAN SARAN Kesimpulan}

Berdasarkan hasil yang diperoleh dari pengabdian berupa pelatihan pembuatan souvenir sabun ini dapat ditarik kesimpulan bahwa kegiatan ini dapat menambah pengetahuan dan ketrampilan ibu-ibu rumah tangga khususnya yang mengikuti pelatihan tentang bagaimana cara meningkatkan penghasilan dengan membuat souvenir sabun.

\section{Saran}

Dalam melaksanakan kegiatan ini harus melakukan pendekatan yang lebih kepada rumah tangga di kecamatan Kaliwates agar lebih memahami pentingnya kegiatan ini dan dapat mengaplikasikan secara berkesinambungan. Selain itu diperlukan monitoring yang berkesinambungan supaya produksi souvenir sabun bisa terus berjalan. Dengan adanya monitoring yang rutin dan berkesinambungan, kelompok ibu rumah tangga di Kecamatan Kaliwates dapat selalu berkoordinasi dan membagi informasi mengenai kendala-kendala yang dilami, sehingga dapat dicari jalan keluar bersama.

\section{DAFTAR PUSTAKA}

Anonim, 2017. https://jemberkab.go.id/disperindag-dan-esdm/\# (diakses tanggal 5 juni 2017)

Emil S, 2011. Dari Limbah Menjadi Rupiah : Mengolah Limbah Industri Skala Rumah Tangga. Lilly Publisher.

Jati, Waluyo. 2017. Pengaruh Strategi Pemasaran Online (Online Marketing Strategy)

Terhadap Minat Beli Konsumen (Studi Kasus Pada Toko Online Shop Azzam

Store). Jurnal Pemasaran Kompetitif. 1(1):127-138

Rita, W.S., Vinapriliani,N. P. E., Gunawan, I. W. G. 2018. Formulasi Sediaan Sabun Padat Minyak Atsiri Serai Dapur (Cymbopogon citratus DC.) Sebagai Antibakteri terhadap Escherichia coli dan Staphylococcus aureus. Cakra Kimia. $6(2): 152-160$ 